\title{
KEMAMPUAN KOGNITIF SISWA PADA KONSEP SISTEM GERAK MANUSIA MELALUI MEDIA CHARTA KELAS VIII SMP NEGERI 1 CIKUPA KABUPATEN TANGERANG
}

\author{
DEDEK MARTHA DEWI \\ Universitas Indraprasta PGRI, SMAN 10 Tangerang \\ e-mail : dedekgirliesbio@gmail.com
}

\begin{abstract}
ABSTRAK
Penelitian ini bertujuan untuk mengetahui kemampuan kognitif siswa pada materi system gerak pada manusia melalui media charta pada siswa kelas VIII E SMP Negeri 1 Cikupa Kabupaten Tangerang. Metode yang digunakan adalah deskriptif. Populasi dalam penelitian ini adalah seluruh siswa kelas VIII SMP Negeri 1 Cikupa Kabupaten Tangerang tahun ajaran 2014/2015. Sampel yang digunakan yaitu siswa kelas VIII E yang terdiri dari 40 orang. Teknik pengambilan data dilakukan secara purpose sampling. Tenik pengumpulan data menggunakan pretest-postest. Instrumen yang digunakan adalah tes objektif berupa pilihan ganda untuk mengukur kemampuan kognitif. Berdasarkan hasil penelitian dapat disimpulkan bahwa penggunaan media pembelajaran charta dapat meningkatkan nilai kemampuan kognitif siswa kelas VIII E SMP Negeri 1 Cikupa Kabupaten Tangerang.
\end{abstract}

Kata Kunci: Media, Charta, Kognitif, Sistem Gerak, Manusia

ABSTRACT

This study aims to determine the cognitive abilities of students on the material system of motion in humans through charta media in class VIII E students of SMP Negeri 1 Cikupa, Tangerang Regency. The method used is descriptive quantitative. The population in this study were all eighth grade students of SMP Negeri 1 Cikupa, Tangerang Regency, in the 2014/2015 academic year. The sample used is class VIII E consisting of 40 people. The data collection technique was carried out by purposive sampling. Data collection techniques using pretest-posttest. The instrument used is an objective test in the form of multiple choice to measure cognitive ability. Based on the results of the study, it can be concluded that the use of charta learning media can increase the value of cognitive abilities of class VIII E students of SMP Negeri 1 Cikupa, Tangerang Regency.

Keywords: Media, Charta, Cognitive, Movement System, Human

\section{PENDAHULUAN}

Pembelajaran akan berjalan lebih efektif apabila guru mempergunakan alat atau media dalam memperjelas penyajian informasi sehingga dapat membangkitkan semangat belajar siswa, ranah kognitif juga berkaitan dengan kemampuan pengetahuan seseorang serta ditingkatkan agar siswa lebih dalam memahami dan menguasai isi pembelajaran (Arsyad, 2007).

Media merupakan segala sesuatu yang dapat menyalurkan pesan (informasi), merangsang pikiran, perasaan serta kemauan siswa dalam suatu proses belajar sehingga tujuan pembelajaran dapat tercapai (Arief, 2005). Media juga bagian yang tidak terpisahkan dari proses belajar mengajar karena media pembelajaran dapat mengatasi keterbatasan pengalaman yang dimiliki oleh para peserta didik. Pemanfaatan media merupakan salah satu komponen pembelajaran yang harus diperhatikan guru dalam setiap pembelajaran namun pada kenyataannya media pembelajaran masih sering terabaikan dengan berbagai alasan antara lain terbatasnya waktu untuk membuat persiapan mengajar, sulit mencari media yang tepat, serta tidak tersedianya biaya untuk membuat media tersebut. Fungsi media pembelajaran selain sebagai alat bantu juga berfungsi sebagai alat penyalur pesan yang dapat menjadikan bahan yang disajikan menjadi jelas maknanya bagi siswa dan tidak bersifat verbalistic (Trianto, 2007). Media pembelajaran dapat membantu proses belajar mengajar menjadi lebih efektif dan efisien. 
Penggunaan media dalam proses pembelajaran dapat membantu siswa dalam memahami materi serta meningkatkan minat proses pembelajaran. Disamping itu media juga berperan dalam proses belajar siswa menjadi lebih interaktif, pengajaran akan lebih menarik, bahan pengajaran akan lebih jelas maknanya sehingga dapat lebih dipahami oleh para siswa.

Media pembelajaran yang baik adalah media yang menarik dan sesuai dengan karakteristik siswa sehingga dapat membangkitkan belajar siswa, salah satu media yang digunakan adalah media gambar (Charta). Media charta dipilih karena gambar secara tidak langsung mempermudah siswa belajar dalam upaya memahami materi pelajaran. Selain itu, media pembelajaran dapat digunakan untuk menyalurkan pesan atau bahan pembelajaran, sehingga dapat merangsang perhatian, minat, pikiran, dan perasaan siswa dalam kegiatan belajar untuk mencapai tujuan belajar. Selain harganya yang murah, charta juga dapat dikreasikan dan didapatkan dengan mudah serta dapat membantu guru dalam pembelajaran di kelas. Media gambar (Charta) juga dapat dijadikan sebagai alat untuk memperjelas suatu permasalahan dalam bidang apapun sehingga kesalahan persepsi dapat dihindari. Materi sistem gerak manusia bagi siswa SMP materi tersebut sulit dipahami maka dengan menggunakan media gambar diharapkan dapat mempermudah siswa dalam memahami materi yang diajarkan dan meningkatkan kemampuan kognitif siswa.

Kognitif berkaitan dengan pemahaman, pertimbangan, pengolahan informasi, pemecahan masalah dan keyakinan (Syah, 2010). Kemampuan kognitif merupakan kemampuan belajar yang berhubungan dengan kemampuan peserta didik menerima konsep setelah mengikuti proses pembelajaran agar tercapai dengan baik. Faktor-faktor yang mempengaruhi kemampuan kognitif siswa diantaranya adalah motivasi, konsentrasi, organisasi, pemahaman, ulangan, perhatian, pengamatan dan tanggapan (Sardiman, 2007)

Proses-proses kognitif yang telibat dalam mencipta umumnya sejalan dengan pengalampengalaman belajar sebelumnya. Meskipun mengharuskan cara berpikir kreatif namun mencipta bukanlah ekspresi kreatif yang bebas sama sekali dan tidak dihambat oleh situasi belajar (Anderson, 2010).

Media bukan hanya alat perantara, seperti televisi, radio, slide, bahan cetakan, namun media juga dapat berupa kegiatan diskusi berupa simulasi bahkan orang lain atau manusia itu sendiri. Pemakaian media dapat membangkitkan motivasi dan rangsangan kegiatan belajar dan bahkan membawa pengaruh-pengaruh psikologis terhadap siswa (Sanjaya, 2007).

Media pembelajaran adalah alat/wahana yang digunakan guru dalam proses pembelajaran untuk membantu penyampaian pesan pembelajaran (Sugandi, 2007). Dalam proses pembelajaran, media berfungsi sebagai pembawa informasi/penyampaian pesan dan isi materi pembelajaran yang diberikan kepada siswa. Manfaat media dalam pembelajaran adalah sebagai berikut: memperjelas pesan agar tidak terlalu verbalistis (banyak kata-kata), mengatasi keterbatasan ruang, waktu, tenaga dan daya indra serta menimbulkan motivasi belajar, berinteraksi secara langsung antara peserta didik dan sumber belajar (Daryanto, 2011).

Media pembelajaran selain sebagai perantara dalam interksi belajar mengajar, juga memiliki peran sebagai alat bantu proses belajar mengajar yang efektif. Suatu media dalam proses pembelajaran juga mampu membangkitkan motivasi serta minat siswa dalam proses pembelajaran, dikarenakan media juga mampu memudahkan penyajian materi yang diberikan, serta dapat meningkatkan pemahaman siswa karena media disajikan dengan menarik perhatian (Rusman, 2008).

Charta adalah serangkaian gambar atau uraian singkat yang tersusun rapi berbentuk lambang-lambang visual yang menunjukkan perbandingan, perbedaan, proses kerja dari awal sampai akhir suatu kejadian. Media charta membuat siswa dapat menangkap ide atau informasi yang diungkapkan dengan kata-kata baik yang tertulis maupun yang diucapkan (Sardiman, 2011).

Pada manusia kemampuan bergerak disebabkan oleh adanya suatu kerja sama antara sistem rangka dan sistem otot, rangka tidak dapat bergerak sendiri bila tidak digerakkan oleh otot. alat gerak pasif berupa tulang/rangka dan alat gerak aktif berupa otot. Kedua alat gerak ini 
akan bekerja sama dalam melakukan pergerakan sehingga membentuk suatu sistem yang disebut sistem gerak (Sudjadi, 2005).

Rangka merupakan rangkaian tulang yang mendukung dan melindungi beberapa organ lunak, terutama dalam tengkorak dan penggul. Kerangka juga berfungsi sebagai alat ungkit pada gerakan, memberi bentuk, sebagai penopang tubuh, melindungi organ-organ dalam, alat gerak pasif, tempat melekatnya otot, dan menyediakan permukaan untuk kaitan otot-otot rangka (Pearce, 2009).

Hubungan antar tulang merupakan tempat bertemunya tulang yang satu dengan tulang yang lain. Hubungan antar tulang ini ada yang dapat mengakibatkan gerak dan ada yang tidak dapat mengakibatkan gerak. Hubungan tulang yang memungkinkan pergerakan disebut persendian atau artikulasi. Bentuk persendian pada rangka tubuh dapat dibedakan atas tiga kelompok, yaitu sinartrosis, amfiartrosis, dan diartrosis (Campbell, 2004).

\section{METODE PENELITIAN}

Metode penelitian yang digunakan adalah metode deskriptif, yaitu penelitian untuk membuat gambaran mengenai kejadian berdasarkan pencarian fakta dengan interpretasi yang tepat. Tujuan penelitian deskriptif adalah untuk membuat deskripsi, gambaran atau lukisan secara sistematis, faktual dan akurat mengenai fakta-fakta, sifat-sifat serta hubungan antar fenomena yang diselidiki (Nazir, 2009).

Populasi yang digunakan adalah seluruh siswa kelas VIII SMP Negeri 1 Cikupa Kabupaten Tangerang. Sampel yang digunakan adalah siswa kelas VIII E yang berjumlah 40 orang. Diambil dengan menggunakan teknik Sample Purposive Sampling.

\section{HASIL DAN PEMBAHASAN}

Penelitian yang dilakukan bertujuan untuk mengetahui kemampuan kognitif siswa pada konsep sistem gerak manusia di kelas VIII SMPN 1 Cikupa Kabupaten Tangerang melalui media Charta. Penilaian dilakukan secara individu dan diukur dengan menggunakan tes pilihan ganda yang diberikan pada awal pembelajaran (pretest) dan akhir pembelajaran (posttest) sebanyak 20 butir soal yang telah diuji terlebih dahulu nilai validitas, reabilitas, tingkat kesukaran dan daya pembedanya. Perbandingan nilai rata-rata kemampuan kognitif siswa sebelum pembelajaran (pretest) dan sesudah pembelajaran (posttest).

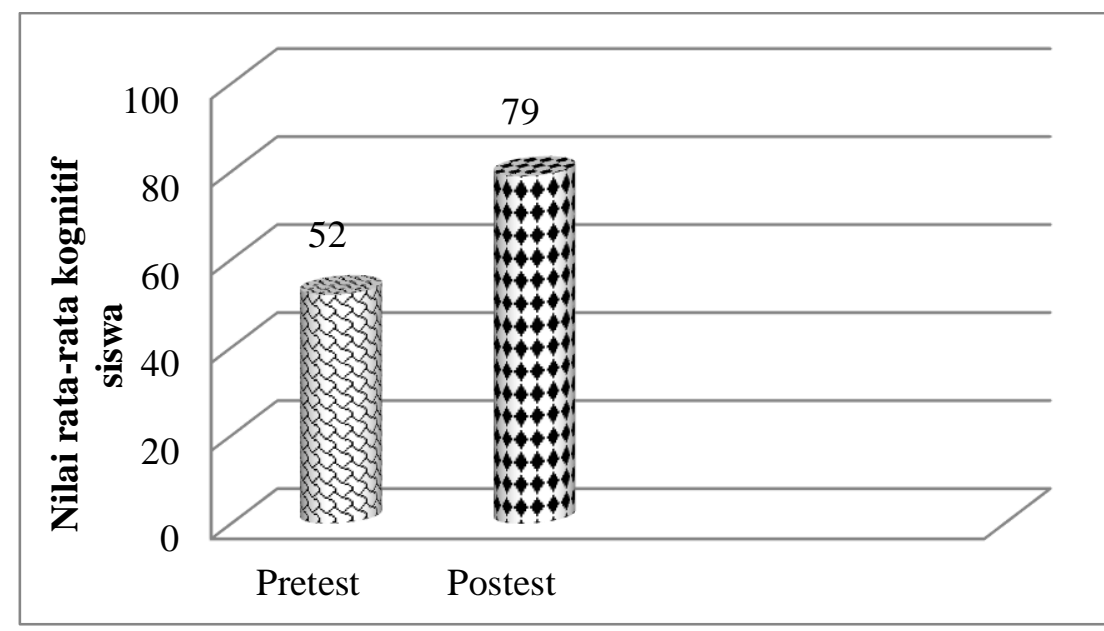

\section{Gambar 1. Nilai rata-rata kognitif siswa pada konsep sistem gerak manusia di Di kelas VIII SMPN 1 Cikupa Kabupaten Tangerang.}

Nilai rata-rata pretest kemampuan kognitif siswa sebesar 52 dengan kategori kurang, hal ini menunjukkan rendahnya pengetahuan awal siswa tentang materi sistem gerak manusia. Rendahnya hasil kemampuan awal siswa dikarenakan kesiapan siswa dalam belajar masih sangat kurang pada saat pembelajaran berlangsung, sehingga siswa kesulitan dalam menjawab 
soal yang diberikan. Kemampuan awal perlu dikondisikan oleh guru sebelum mengajar agar siap mengikuti pembelajaran. Mengkondisikan siswa agar siap menerima pelajaran seperti mengadakan apersepsi, memberikan motivasi pada siswa agar dapat menilai, dan menghayati pelajaran serta menguasai materi dengan bahasa yang mudah, dan jelas dipahami.

Setelah diberikan media pembelajaran charta pada siswa menunjukkan peningkatan nilai kognitif siswa, hal tersebut dilihat dari hasil nilai rata-rata posttest yang menunjukkan sebesar 79 dengan kategori baik. Proses pembelajaran berlangsung dengan lancar dan seluruh siswa melakukan kegiatan pembelajaran dengan baik. Rata-rata siswa mendapatkan nilai posttest yang lebih tinggi dibanding nilai Ketuntasan Minimum (KKM) di SMPN 1 Cikupa Kabupaten Tangerang yaitu sebesar 70. Peningkatan kemampuan kognitif yang ditunjukkan oleh nilai Gain, nilai rata-rata indeks gain yang didapat adalah 0,76 dengan kategori baik. Apabila nilai tes terakhir (posttest) lebih baik dari pada nilai tes awal (pretest) maka dapat diartikan bahwa kegiatan pembelajaran yang digunakan telah berjalan dengan baik. Tes akhir berfungsi menilai kemampuan siswa mengenai penguasaan materi pelajaran setelah pembelajaran dilaksanakan (Sugiyono, 2010). Dengan demikian, melalui hasil tes akhir dapat diketahui keberhasilan program pembelajaran yang telah dilakukan dalam rangka mencapai tujuan atau kompetensi yang telah ditetapkan (Rustaman, 2011).

Indikator kemampuan kognitif terdiri atas 6 jenjang, yaitu mengingat, memahami, mengaplikasi, menganalisis, mengevaluasi dan mencipta. Soal tes kemampuan kognitif siswa pada penelitian ini berupa 20 soal pilihan ganda dengan jenjang kognitif mulai dari $\mathrm{C} 1$ sampai dengan $\mathrm{C} 4$.

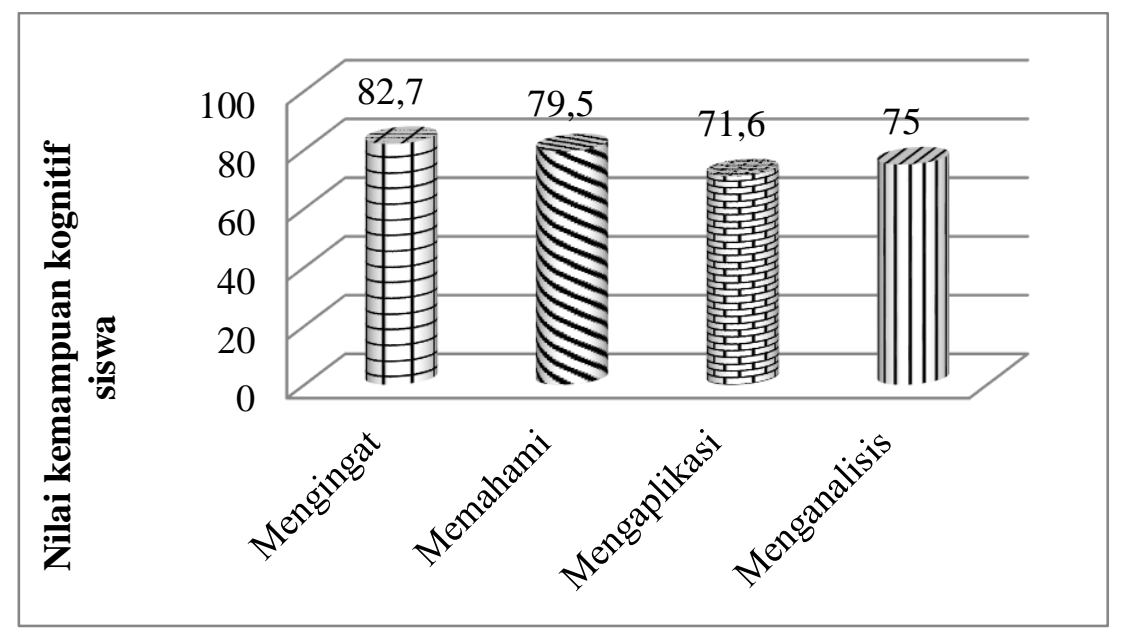

\section{Gambar 2. Nilai Kemampuan Kognitif Siswa Pada Setiap Jenjang}

Jenjang kemampuan kognitif yang menempati nilai tertinggi yaitu jenjang mengingat (C1) memperoleh nilai sebesar 82,7 dan termasuk kedalam kategori sangat baik hal ini menunjukkan bahwa sebagian besar siswa dapat mengingat dengan baik materi sistem gerak pada manusia. Hal ini dikarenakan mengingat merupakan jenjang kognitif yang paling mudah dibandingkan dengan jenjang kognitif yang lain. Mengingat merupakan kemampuan kognitif yang paling rendah tingkatannya (Widodo, 2006). Kemampuan kognitif siswa dengan indikator mengingat yaitu mengacu pada kemampuan mengenal/mengingat materi yang sudah dipelajari dari yang sederhana sampai hal-hal yang sukar (Sudjana, 2011). Kemampuan kognitif pada indikator mengingat dengan menggunakan media charta dapat mengikuti pembelajaran yang sangat tinggi. Sehingga siswa dapat mengingat, memahami, mengaplikasi dan menganalisis dengan menggunakan media pembelajaran charta yang baru diterapkan disekolah dan masih dirasakan baru oleh siswa.

Untuk mengetahui kemampuan kognitif siswa lebih spesifik, dilakukan pembagian nilai siswa dalam beberapa kategori. 


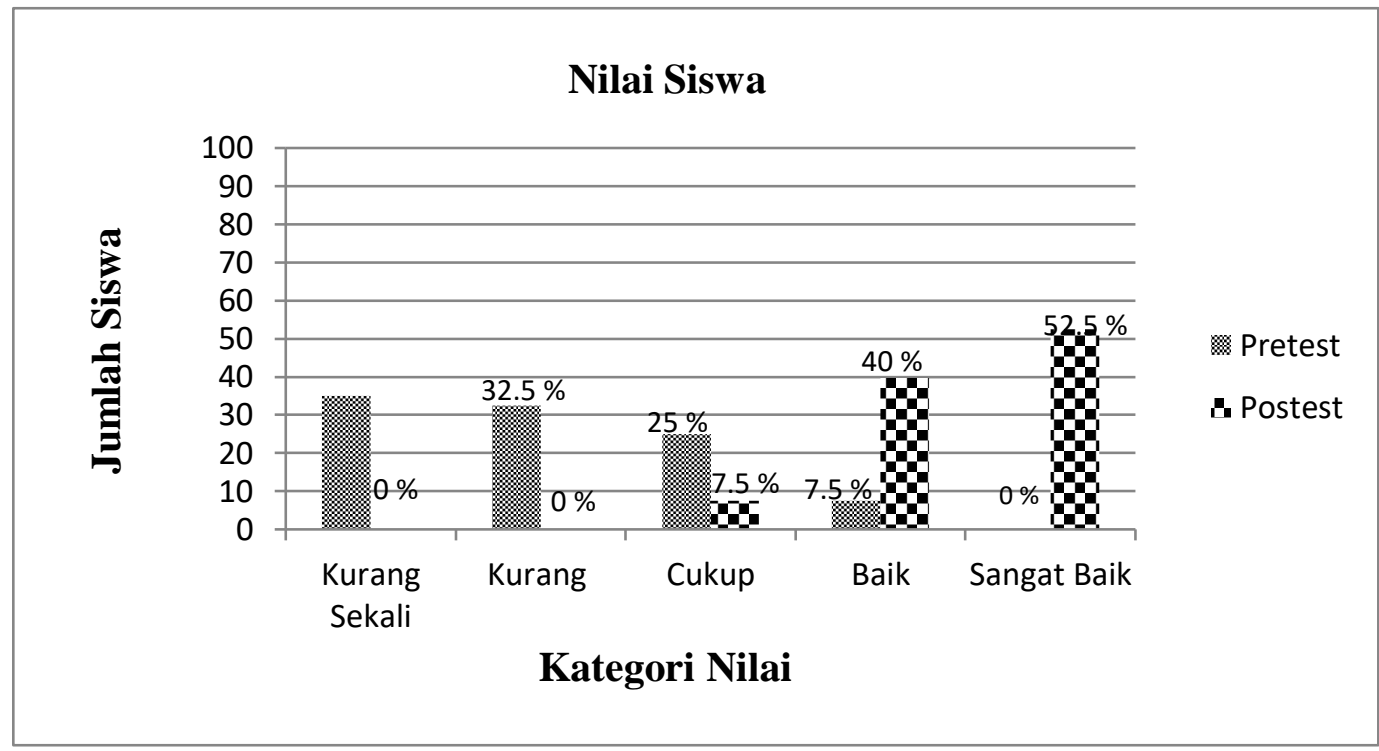

\section{Gambar 3. Kategori nilai kemampuan kognitif siswa}

Pengelompokan nilai siswa berdasarkan kategori kemampuan kognitif dibagi menjadi 5 kategori yaitu sangat baik, baik, cukup, kurang dan kurang sekali. Hasil perhitungan pretestpostest kemampuan kognitif siswa kelas VIII SMPN 1 Cikupa Kabupaten Tangerang menunjukkan nilai pretest persentase tertinggi terdapat pada nilai dengan kategori kurang sekali sebesar 35\% siswa. Sedangkan pada nilai postest persentase tertinggi terdapat pada nilai dengan kategori sangat baik sebesar 52,5\% siswa. Sementara itu, pada nilai pretest siswa juga memperoleh nilai dengan kategori kurang sebesar 32,5\% siswa, nilai dengan kategori cukup sebesar $25 \%$ siswa.

Pada nilai postest terdapat siswa yang memperoleh nilai kategori sangat baik sebesar $52,5 \%$ siswa, nilai dengan kategori baik sebesar $40 \%$ siswa dan memperoleh nilai dengan kategori cukup sebesar 7,5\% siswa. Dengan demikian siswa berada pada 3 kategori dari 5 kategori kemampuan kognitif, variasi nilai tersebut menggambarkan perbedaan kemampuan kognitif tiap-tiap individu. Secara umum siswa dalam satu kelas memiliki kemampuan kognitif yang bervariasi dan terbagi atas tiga kelompok yaitu kelompok pandai, kelompok sedang dan kelompok kurang, akan tetapi pada penilaian postest tidak ada siswa yang berkemampuan kurang. Hal tersebut bahwa pembelajaran media charta meningkatkan kemampuan kognitif siswa. Hal tersebut terjadi karena media pembelajaran charta mempunyai kelebihan yang menuntut peran aktif siswa dalam memahami materi/konsep yang diajarkan (Djamarah, 2008).

Berdasarkan hasil penelitian, dapat diketahui bahwa nilai kognitif siswa rata-rata 79. Nilai kemampuan kognitif sudah memenuhi nilai KKM dengan nilai 70. Hasil postest menunjukkan $88 \%$ siswa memperoleh nilai kategori sangat baik dan baik atau memperoleh nilai lebih dari 70 .

\section{KESIMPULAN}

Berdasarkan penelitian yang telah dilakukan dapat disimpulkan bahwa penggunaan media pembelajaran charta dapat meningkatkan kemampuan kognitif siswa pada konsep sistem gerak kelas VIII SMPN 1 Cikupa Kabupaten Tangerang, maka dapat diperoleh nilai rata-rata kemampuan kognitif siswa sebesar 79 termasuk dalam kategori baik. Pengkategorian berdasarkan nilai postest yaitu 52,5\% sangat baik, $40 \%$ baik, 7,5\% cukup serta tidak ada siswa yang berkemampuan kurang dan kurang sekali.

\section{DAFTAR PUSTAKA}

Anderson, W. L. \& D. R. Krathwohl. 2010. Kerangka Landasan Untuk Pembelajaran, Pengajaran, dan Asesmen Revisi Taksonomi Pendidikan Bloom. Pustaka Pelajar, 
Yogyakarta: $168 \mathrm{hlm}$.

Arsyad, A. 2007. Media Pembelajaran. PT Raja Grafindo Persada.Jakarta : xi + 192 hlm.

Arief, S., R. Rahardjo., A. Haryono \& Rahardjito.Media Pendidikan: Pengertian, Pengembangan dan Pemanfaatannya. 2005. PT Raja Grafindo Persada. Jakarta: xi + $332 \mathrm{hlm}$.

Campbell, N. A., J.B. Reece, L.G. Mitchell. 2004. Biologi Edisi kelima-Jilid 2.Terj.Dari Biology.Fifth Edition. Oleh manalu. W. Erlangga, Jakarta: xxii $+472 \mathrm{hlm}$.

Daryanto. 2011. Media Pembelajaran. Bandung: Satu Nusa.

Djamarah, S. B. 2008. Psikologi Belajar. Rineka Cipta. Bandung : x+263 hlm.

Nazir, M. 2009. Metode Penelitian. Ghalia Indonesia, Jakarta : 536 hlm.

Pearce, E. C. 2009. Anatomi dan Fisiologi Untuk Paramedis.Terj.dari Anatomy dan Physiology for Nurses.oleh handoyo, S.Y., penerbit PT. Gramedis Pustaka Utama, Jakarta: vi + $416 \mathrm{hlm}$.

Rusman. 2008. Prinsip-Prinsip dan Teknik Evaluasi Pengajaran. PT. Remaja Rosdakarya, Bandung: $\mathrm{v}+138 \mathrm{hlm}$

Rustaman, N. Y. 2011. Asesmen Pendidikan IPA. Proceeding Seminar Penataran Guru-guru NTT di Jurusan Pendidikan Biologi. FPMIPA UPI, Bandung: $163 \mathrm{hlm}$.

Sadirman, 2006. Belajar dan Faktor-Faktor yang Mempengaruhinya. Rineka Cipta, Jakarta: v $+195 \mathrm{hlm}$.

Sanjaya. 2007. Teori Pembelajaran. Semarang: Universitas Negeri Semarang Press.

Sardiman, A. M. 2007. Interaksi dan Motivasi Belajar Mengajar. PT Raja Grafindo Persada.Jakarta : ix + $236 \mathrm{hlm}$.

Sudjadi, B.2005. Biologi Sains dalam Kehidupan. Yudhistira. Jakarta: 51 hlm.

Sugandi.2007. Metodologi Penelitian Pendidikan. Bumi Aksara, Jakarta: v $+233 \mathrm{hlm}$.

Sudjana, N. 2011. Penilaian Hasil Proses Belajar Mengajar. PT. Remaja Rosdakarya, Bandung : xi $+168 \mathrm{hlm}$.

Sugiyono.2010. Metodologi Penelitian Pendidikan. Bumi Aksara, Jakarta: v $+233 \mathrm{hlm}$.

Syah. 2010. Strategi pembelajaran berbasis kompetensi. Gaung Persada Press.Jakarta: $\mathrm{x}+170$ hlm.

Trianto. 2007. Model Pembelajaran Terpadu dalam Teori dan Praktik. Prestasi Pustaka Publishe. Jakarta: v + 212 hlm.

Widodo, A. 2006. Taksonomi Bloom dan Pengembangan Butir Soal. Buletin Puspendik. 3(2): $18-29$ 